УДК 811/111

ББК 81.2

DOI: https://doi.org/10.17308/lic.2021.3/3583

\title{
МУЗЫКАЛЬНЫЕ ИНСТРУМЕНТЫ В ХУДОЖЕСТВЕННОЙ КАРТИНЕ МИРА Э. БЁРДЖЕССА
}

\author{
Л. В. Коробко \\ Военно-воздушная академия имени Н. Е. Жуковского и Ю. А. Гагарина

\section{MUSICAL INSTRUMENTS \\ IN THE LITERARY WORLD VIEW OF ANTHONY BURGESS}

\author{
L. V. Korobko \\ Air Force Academy named after N. E. Zhukovsky and Yu. A. Gagarin
}

\begin{abstract}
Аннотация: в статье анализируются контексты, в которых используются названия музыкальных инструментов в художественных текстах Энтони Бёрджесса, рассматривается специифика индивидуально-авторского восприятия и отражения музыки в художественной картине мира писателя на примере анализа контекстов, содержащих описание музыкальных инструментов. Цель работы состоит в выявлении специфики вербальной экспликачии музыкальных инструментов в художественной картине мира Энтони Бёрджесса. Работа выполнена с использованием таких методов исследования, как метод контекстуального анализа и метод компонентного анализа с опорой на словарные дефиниции. В художественных текстах Э. Бёрджесса репрезентируются как типы музыкальных инструментов (strings (струнные), wind instruments (духовые инструменты), drums (ударные) и brass (медные духовые)), так и непосредственные их наименования (truтреt (труба), drum (барабан), ріапо (фортепиано) и др.). Установлено, что вербальная репрезентация музыкальных инструментов в художественной картине мира Э. Бёрджесса отличается высокой степенью метафоризации. С позиции аксиологии отмечается мелиоративная, (квази)пейоративная и нейтральная маркированность анализируемых лексем. Отдельныле музыкальные инструменты получают детальное описание с указанием их ивета, материала изготовления, локализации, характеристики звучания. Анализ контекстов, включающчи названия музыкальных инструментов, в художественных текстах Э. Бёрджесса позволяет утверждать, что писатель в своих литературных произведениях придает высокую степень значимости звучанию музыкальных инструментов в прочессе раскрытия определенных художественных смыслов.
\end{abstract}

Ключевые слова: музыкальный инструмент, художественный текст, индивидуально-авторская картина мира, Энтони Бёрджесс, лексема, метафора.

\begin{abstract}
Anthony Burgess, examines the specifics of individual-and-author's perception and reflection of music in the writer's literary world image based on the analysis of the contexts containing a description of musical instruments. The purpose of the paper is to identify the specifics of verbal explication of musical instruments in the literary world image of Anthony Burgess. The work was carried out using such research methods as the contextual analysis method and the component analysis method based on dictionary definitions. The certain types of musical instruments (strings, wind instruments, drums and brass) and their direct names (trumpet, drum, piano, etc.) are represented in the literary texts of A. Burgess. It has been established that the verbal representation of musical instruments in the literary world image of A. Burgess is distinguished by a high degree of metaphorization. From the position of axiology, the positive, (quasi) negative and neutral labeling of the analyzed lexemes is noted. Some musical instruments receive a detailed description with the indication of their color, material of production, localization, and sound characteristics. The analysis of the contexts that include the names of musical instruments in the literary texts of A. Burgess allows us to state that the writer in his literary works gives a high degree of importance to the sound of musical instruments in the process of revealing certain artistic meanings.
\end{abstract}

Key words: musical instrument, literary text, individual-and-author's world image, Anthony Burgess, lexeme, metaphor.

(С) Коробко Л. В., 2021

Контент доступен под лицензией Creative Commons Attribution 4.0 License.

The content is available under Creative Commons Attribution 4.0 License. 


\section{Введение}

Тема формирования индивидуально-авторской картины мира является одним из актуальных вопросов современной лингвистики. Язык аккумулирует знания людей о мире, и это «позволяет человеку объединить весь опыт в единую картину мира и заставляет его забыть о том, как раньше, до того как он изучил язык, он воспринимал окружающий мир» $[1$, c. 51$]$.

Индивидуальная картина мира является результатом когнитивной деятельности одного человека и представляет собой квинтэссенцию постоянных и изменчивых элементов. «Индивидуальное в языковой личности, с одной стороны, формируется через внутреннее отношение человека к языку, через становление личностных смыслов языка, которые определяют ее индивидуальные варианты ценностного отношения к языку. С другой стороны, языковая личность оказывает заметное влияние на становление языковых традиций» [2, с. 11].

Отдельного внимания заслуживают индивидуальные картины мира представителей творческих профессий, создающих художественные произведения. Поэтому, наряду с национальной и индивидуальной картиной мира, выделяется также художественная картина мира. З. Д. Попова и И. А. Стернин отмечают, что художественная картина мира опосредована дважды: во-первых, посредством языка, а во-вторых, через индивидуальное сознание автора, основываясь на его субъективно-личностных представлениях о мире [3, с. 40]. Особенность художественной картины мира выражается в выборе средств художественной выразительности, композиции произведения и содержательных элементов. В художественной картине мира может также найти свое отражение национальная картина мира. «Это позволяет интерпретировать использованные языковые средства, присутствующие в тексте, как активизирующие те или иные культурноспецифические знания о мире, а сам текст - как коммуникационный результат, порожденный в тех или иных коммуникационных условиях» $[4$, с. 8$]$.

Целью настоящей статьи является определение особенностей вербальной экспликации музыкальных инструментов в индивидуально-авторской картине мира Энтони Бёрджесса.

Энтони Бёрджесс - английский романист, композитор и критик, романы которого создают сатирический образ мира и примечательны словотворчеством. Однако одним из центральных среди доминантных смыслов индивидуально-авторской картины мира Э. Бёрджесса была музыка. Писатель сочинил несколько музыкальных произведений, прежде чем выпустил в свет свои первые литературные произведения.

\section{Материалы и методы}

Материалом для исследования послужили художественные тексты Энтони Бёрджесса «A Clockwork Orange» («Заводной апельсин», 1962), «Earthly Powers» («Силы земные», 1980), «One Hand Clapping» («Однорукий аплодисмент», 1961), «Time for a Tiger» («Время тигра», 1956), «Tremor of Intent» («Трепет намерения», 1966).

В работе были использованы следующие методы исследования: метод контекстуального анализа и метод компонентного анализа с опорой на словарные дефиниции.

\section{Результаты исследования}

Музыкальные инструменты занимают важное место в пространстве художественного произведения Э. Бёрджесса. Включение в текст номинаций определенных музыкальных инструментов раскрывает художественные предпочтения автора.

Воспроизведение музыки в художественной картине мира Энтони Бёрджесса репрезентируется посредством описания типов музыкальных инструментов (1) и через непосредственную характеристику музыкальных инструментов (2).

1. Типы музыкальных инструментов. Типы музыкальных инструментов реализуются в текстах писателя посредством таких лексических единиц, как strings (струнные), wind instruments (духовые инструменты ), druтs (ударные) и brass (медные духовые).

Слово STRINGS (струнные) со значением «the section of an orchestra which consists of stringed instruments played with a bow» [5] (музыкальные инструменты со струнами, игра на которых осуществляется с помощью смычка) реализуется в следующих примерах:

...his massed strings were a bed for physical passion [6] (...лавина струнных символизировала плотскую страсть [7]);

Then in a passion of plucked strings and little cracked bells she let fly at a weeping child, pushed by his fellows into a sugar-bin [8] (Потом под страстное бряцание струн и маленьких треснувших колокольчиков она бросилась к скулившему ребенку, которого собратья толкнули в мешок с сахаром [9]).

Звучание струнных музыкальных инструментов ассоциируется со страстью, что репрезентируется посредством субстантивной лексемы passion (страсть).

...came the violin solo above all the other strings, and those strings were like a cage of silk around my bed [10] (...вступила скрипка соло, сразу возвысившись над всеми другими струнными, которые будто шелковой сетью сплелись над моей кроватью [11]). 
В данном контексте используется авторская метафора, звуки струнных инструментов сравниваются с шелковой сетью или золотой клеткой (a cage of silk).

Указывается также расположение данной невидимой сети - around my bed (над кроватью), что говорит о том, что мелодия отграничивает слушателя от окружающего мира, сплетая вокруг него сеть из музыки, околдовывая, не позволяя выйти из созданного состояния, удерживая его заложником своей красоты [12].

...so it was J. S. Bach I had, the Brandenburg Concerto just for middle and lower strings. And, slooshying with different bliss than before... [10] (...и я вынул И. С. Баха, «Бранденбургский кониерт» для струнных среднего и низкого звучания. Слушая его с наслаждением теперь совсем другого рода... [11]).

В представленном контексте дается качественная характеристика звука. Указывается высота звучания струнных инструментов - middle and lower strings, струнные инструменты среднего и более низкого звучания.

Репрезентируются также эмоции, вызванные прослушиванием струнных инструментов-slooshying with different bliss than before. Речь идет о восторге, наслаждении, доставляемом музыкой, однако описываемый восторг отличается от ранее испытанного.

Актуализируется признак получения удовольствия от прослушивания струнной музыки.

There it was then, the bass strings like govoreeting away from under my bed at the rest of the orchestra... [10] (Вот басовые струнные, заговорили прямо уменя из-под кровати, отзываясь оркестру... [11]).

В данном примере также присутствует характеристика струнных инструментов - bass strings, «a bass instrument or voice produces low notes» [13] (басовый инструмент или голос производит низкие ноты).

Наблюдается метафора-олицетворение, музыкальные инструменты наделяются способностью говорить, даже переговариваться - govoreeting away [12].

Глагол govoreet является примером молодежного сленга - надсат и, согласно трактовке Э. Берджесса, означает «to speak or talk» [10] (говорить, общаться).

Указывается локализация инструментов - from under my bed (из-под кровати) и собеседник - the rest of the orchestra (оркестр).

Таким образом, басовые струнные как будто затаились и ждут подходящего момента, чтобы проявить всю свою мощь и заговорить в полную силу, слившись с оркестром воедино, став его частью.

Таким образом, номинация strings получает качественную характеристику: указание высоты звучания струнных инструментов - middle and lower strings (струнные среднего и низкого звучания), bass strings (басовые струнные).
Номинация WIND INSTRUMENT (духовой инструмент) имеет значение «а musical instrument that you blow into in order to produce sounds, such as a flute, a clarinet, or a recorder» [5] (музыкальный инструмент, действующий посредством вдувания струи воздуха, например, флейта, кларнет или блок-флейта). Ср.:

I was with the wind instruments... [10] (Я сидел в гpynne dyxовblx... [11]).

Номинация wind instruments нейтральна, поскольку отсутствует оценочный или характерологический компонент. Наблюдается лишь констатация факта: нахождение в оркестре в группе духовых инструментов.

В следующих контекстах упоминаются два типа музыкальных инструментов - BRASS (медные духовые ) и DRUMS (ударные):

Discordant lower brass symbolised the situation of the men in the boat [6] (Несоответствующий им низкий звук медных духовых должен был символизировать состояние людей в лодке [7]).

Лексема brass (медные духовые) означает «the section of an orchestra which consists of brass wind instruments such as trumpets and horns» [5] (музыкальные инструменты, сделанные из металла, такие как труба и тромбон).

Звучание музыки описывается прилагательным lower brass (низкий звук медных духовых).

And then the promise loomed, the declaration of the Angel of the Lord, and the rhythm of ancient drums pulsed in imperceptible gradations of acceleration [6] (И вот обещание приблизилось, Ангел Господень возвещал, ритм древних тимпанов неощутимо ускорялся [7]).

Лексема DRUMS (ударные) имеет значение «а drum kit or set of drums» [5]; «a musical instrument consisting of a skin stretched tightly over a round frame. You play a drum by beating it with sticks or with your hands» [Ibid.] (барабанная установка или ударные музыкальные инструменты; музыкальный инструмент из кожи, плотно обтянутой вокруг круглого каркаса. Игра осуществляется посредством ударов палочек или рук). Таким образом, данная лексема используется для указания как отдельного инструмента (барабан), так и для наименования типа музыкальных инструментов (ударные).

Отмечается возраст музыкальных инструментов - ancient (древний) и скорость игры на них - rhythm pulsed in imperceptible gradations of acceleration (pumм неошутимо ускорялся).

2. Наименования музыкальных инструментов. Наименования музыкальных инструментов представлены следующими лексемами: trumpet (mpуба), drum (барабан), ріапо (фортепиано), flute (флейта), organ (орган), horn (рожск), violin (скрипка), trombone (тромбон), guitar (гитара), harpsichord (клавесин), obое (гобой), saxорhone (саксофон), kettledrums (ли- 
тавры), clarinet (кларнет), harp (арфа), bassoon (фагот), gong (гонг), cymbal (цимбала), ріре (труба), jangles (колокольчики), viola (альт), reed (свирель). Рассмотрим примеры.

Слово TRUMPET (mpуба) означает «а musical instrument of the brass family which plays quite high notes. You play the trumpet by blowing into it» [5] (духовой медный музыкальный инструмент с высоким звуком, игра на котором осуществляется путем дуновения в него). Ср.:

... and behind my gulliver the trumpets three-wise silverflamed... Oh, it was wonder of wonders [10] (2deто за головой, трехструйные, искрились пламенные трубы... О, чудо из чудес! [11]).

Звучание трубы описывается как «чудо из чудес» (wonder of wonders), что говорит о восхищении слушателя музыкой. Также в фокусе внимания находится метафорическая составляющая, звуки трубы отождествляются с природной стихией - огнем, что репрезентируется посредством глагола silverflame [12].

Далее номинация trombones употребляется в одном контексте с лексемой KETTLEDRUMS (литавра). Слово kettledrum (литавра) интерпретируется как «а large bowl-shaped drum which can be tuned to play a particular note» [5] (большой ударный музыкальный инструмент в форме чаши, который может быть настроен для исполнения определенной ноты). В тексте данная лексема используется в форме множественного числа kettledrums. Cp.:

So I stuck my little fingers real deep in my ookos, but the trombones and kettledrums blasted through gromky enough [10] (Я заткнул иshi пальцами, но тромбонь с литаврами все равно прорьвались [11]).

В настоящем примере звучание музыкальных инструментов репрезентируется глаголом blast и прилагательным gromky (громкий). Лексема blast означает «to produce a lot of loud noise, especially music» [13] (производить громкий шум, особенно от музыки). Акцент делается на громкости звучания тромбонов и литавр.

I was slooshying more like malenky romantic songs, what they call Lieder, just a goloss and a piano, very quiet and like yearny, different from when it had been all bolshy orchestras and me lying on the bed between the violins and the trombones and kettledrums [10] (Перешел на короткие лирические песенки, так называемые «зонги» - просто голос и фортепьяно, тихие, вроде как даже тоскливые, не то что раньие, когда я слушал большие оркестры, лежа в кровати и воображая себя среди скрипок, тромбонов и литавр [11]).

В данном контексте фортепьяно (piano) противопоставляется скрипке (violins), тромбону (trombones) и литаврам (kettledrums).

Так, звуки фортепиано описываются прилагательными quiet (тихий) и yearny (тоскливый), усиленными наречием very (очень), и относятся к инструментам, игра на которых используется в качестве аккомпанемента романтическим песням (malenky romantic songs).

Игре на скрипке, тромбонах и литаврах, напротив, придается особая значимость и масштабность, что подчеркивается отнесенностью к большим оркестрам (bolshy orchestras).

В следующем контексте присутствует указание двух музыкальных инструментов: FLUTE (флейта) и $O B O E$ (гобой):

Then flute and oboe bored, like worms of like platinum, into the thick thick toffee gold and silver. I was in such bliss... [10] (Потом ворвались флейта с гобоем, ввинтились, словно платиновые черви в сладчайиую изобильную plott из золота и серебра. Невероятнейшее наслаждение... [11]).

Номинация оboе (гобой) означает «а wooden musical instrument like a narrow tube, which you play by blowing air through a reed» [5] (деревянный музыкальный инструмент похожий на узкую трубку, для игры необходимо выдувать воздух через трость или язычок).

Звучание флейты и гобоя описывается с помощью метафоры и сравнения: bored, like worms of like platinum, into the thick thick toffee gold and silver. Актуализируется признак всепоглощающего и всеобъемлющего воздействия музыки, подчеркивается ее ценность и духовность [12].

Лексема flute (флейта) в значении «а musical instrument like a thin pipe, that you play by holding it across your lips, blowing over a hole, and pressing down buttons with your fingers» [13] (музыкальный инструмент в виде тонкой трубки, чтобы играть на нем, необходимо приложить его к губам и дуть в отверстие, нажимая на клавиши пальцами). Ср.:

I was in like a big field with all flowers and trees, and there was a like goat with a man's litso playing away on a like flute [10] (...я оказался вроде как на широкой поляне среди иветов и деревьев, и там же был вроде как козел с человеческим litsom, играющчй вроде как на флейте [11]).

В представленном контексте наблюдается мифопоэтическая составляющая лексемы flute (флейта), которая может быть отражена посредством семантико-когнитивной цепи: field (поле) - flowers (цветы) trees (деревья) - goat-man (козел с человеческим лиизом) - flute (флейта). Поле, цветы, деревья, получеловек-полукозел, играющий на флейте, переносят читателя в пространство нереального мира мифа и сказки. Данные образы вызывают приятные ощущения в сознании человека, поэтому можно говорить о мелиоративной коннотации лексемы flute.

Debussyish consecutive fourths on oboes and clarinets [6] (Затем последовали кварты гобоев и кларнетов в стиле Дебюсси [7]); 
Solo oboe here? [6] (Тут соло гобоя? [7]).

В вышеприведенных контекстах отмечается нейтральная коннотация наименования $O B O E$ (гобой).

Лексема GUITAR (гитара) имеет значение «а musical instrument with six strings that you play by pulling the strings with your fingers or with a plectrum» [13] (шестиструнный музыкальный инструмент, для игры на котором необходимо зажимать струны пальцами или плектром). Ср.:

The stereo was on again and was playing a very sick electronic guitar veshch [10] (Проигрыватель опять вовсю играл, причем какую-то жуткую электронную вещъь на гитаре (перевод наш. - Л. К.);

The round man with the guitar, Peter or Paul or something, improvised a silly jingle to the tune of 'Chopsticks'... [14] (Толстяк с гитарой (Питер? Пол?) тотчас выдал дурачкую импровизачию на мотив «собачьего вальса» [15]);

... she switched off the radiogram they had which had been playing all twanging guitars, very teenage [16] (...она выллючила запись, которую крутили по радио, сплошные гитары гнусавые, для одних тинейджеров [17]).

Произведения, исполняемые на гитаре (guitar), получают негативную характеристику, что репрезентируется адъективными квалификаторами very sick veshch (жуткую вещь), a silly jingle (дурацкая импровизация), very teenage (для одних тинейджеров). Отмечается указание на разновидность гитары - электрогитара (electronic guitar) и звучание - twanging (гнусавые). Лексема guitar аксиологически нейтральна, однако ее лексическое окружение придает ей квази-отрицательную маркированность.

Третий лексико-семантический вариант слова ORGAN (орган) - «a large musical instrument used especially in churches, with keys like a piano and large pipes that air passes through to produce the sound» [13] (большой музыкальный инструмент, используемый в основном в церквях, с клавишами, как у пианино и огромными трубами, через которые проходит воздух для создания звука) - реализуется в следующих примерах:

... and then I let the simple music for organ only come belting out with a growwwwowwwwowwww [10] (...u я сразуврубил орган, взревевший УУУУУУУУУУУУУУУ [11]);

... the electric organ playing something sort of very triumphant, almost like the second wedding march [16] (...электроорган играл что-то очень триумфальное, почти типа второго свадебного марша [17]).

Звучание органа (organ) репрезентируется глаголом belt out. Фразовый глагол belt out трактуется как «to sing a song or play an instrument loudly» [13] (петь песню или играть на музыкальном инструменте очень громко). Описывается громкость звучания музыкального инструмента. Наблюдается указание на тип органа - electric organ (электроорган). Музыка, исполняемая органом, получает положительную оценку - very triumphant, almost like the second wedding march (очень триумфальное, почти типа второго свадебного мариа).

Лексема BASSOON (фагот) определяется как «а large musical instrument of the woodwind family that is shaped like a tube and played by blowing into a curved metal pipe» [5] (духовой деревянный музыкальный инструмент в форме трубы, для игры на котором необходимо дуть в изогнутую металлическую трубку). Ср.:

... what I was playing was like a white pinky bassoon made of flesh and growing out of my plott, right in the middle of my belly... [10] (я играл на каком-то таком розоватом фаготе, который был частью моего тела и рос из середины живота... [11]).

В данном примере представлены следующие параметры фагота (bassoon): цвет - white pinky (розоватьй), материал - flesh (плоть), месторасположение - growing out of my plott, right in the middle of my belly (был частью моего тела и рос из серединь живота).

Анализируемый контекст представляет собой описание сна, однако в нем содержится имплицитный метафорический смысл [12]. Так, любовь к музыке настолько сильна, что главный герой не мыслит себя вне музыки, она как будто стала его неотъемлемой частью, без которой невозможно его существование.

В следующих контекстах представлен ряд музыкальных инструментов. Ср.:

... a jazzy concerto with saxophones and wa-wa trumpets and the rest of the nonsense [6] (...на сочинение джазового концерта с саксофоном, трубами и прочим вздором [7]);

It would have been proper for the man who had once been his brother to celebrate this elevation in some Berliozian Te Deum scored for quadruple woodwind, ten horns, six trumpets, the same of trombones... [6] (Было бы весьма уместным, если бы человек, когда-то бывший его братом, восславил бы его возвышение чем-то вроде берлиозовского «Tе Deuт» для учетверенного числа деревянных духовых, десяти рожков, шести труб, стольких же тромбонов... [7]);

Pianissimo chords on muted horns and trombones and a slack roll on the deepest kettledrum [6] (Зазвучали пианиссимо приглушенные деревянные духовые и тромбоны, и дробь басового барабана [7]).

Представленные номинации не получают оценочного и характерологического описания.

Рассмотрение наименований музыкальных инструментов показало, что в основе классификации музыкальных инструментов лежат следующие вербальные квалификаторы: «громкость звучания», «материал», «местоположение», а также дается их оценка (таблица). 
Аксиологическая маркированность наименований музыкальных инструментов в художественных текстах Э. Бёрджесса

\begin{tabular}{|c|c|c|c|}
\hline $\begin{array}{c}\text { Наименование } \\
\text { музыкального } \\
\text { инструмента }\end{array}$ & $\begin{array}{c}\text { Положительная } \\
\text { маркированность }\end{array}$ & $\begin{array}{c}\text { Отрицательная } \\
\text { маркированность }\end{array}$ & Нейтральная маркированность \\
\hline 1 & 2 & 3 & 4 \\
\hline trumpet (труба) & $\begin{array}{c}\text { wonder of wonders (чудо из } \\
\text { чудес), angel (ангельский), } \\
\text { sketched a diffident flourish } \\
\text { (изобразили робкую надежду), } \\
\text { silverflamed (искрились) }\end{array}$ & $\begin{array}{c}\text { wa-wa (завывающиий), corny } \\
\text { (банальный) }\end{array}$ & $\begin{array}{l}\text { signaled (пропели), } \\
\text { muted (приглушенный), } \\
\text { little (маленький) }\end{array}$ \\
\hline drum (барабан) & - & - & $\begin{array}{l}\text { beat easy rhythms (отбивали } \\
\text { легкие ритмы), languidly } \\
\text { spanked (лениво били), lit- } \\
\text { tle (маленький), а soft thud } \\
\text { (приглушенный удар) }\end{array}$ \\
\hline $\begin{array}{l}\text { (grand) ріапо } \\
\text { (фортепиано, } \\
\text { пианино, рояль) }\end{array}$ & - & $\begin{array}{c}\text { worn (разбитый), тиst have cost } \\
\text { a few quid to ипtипе (безнадежно } \\
\text { paccтроенное), rotten, broken- } \\
\text { down, pounded (paccmpoенное), } \\
\text { old (cmарый), very quiet and like } \\
\text { yearny (тихие, вроде как даже } \\
\text { тоскливые) }\end{array}$ & $\begin{array}{c}\text { cottage (небольшое), tropicalized } \\
\text { (испьтавшее тропики), Paris } \\
\text { (парижское), white baby (белый } \\
\text { кабинетный), harmless twaddle } \\
\text { (безобидно бренчать), full } \\
\text { поіsе (громкие звуки) }\end{array}$ \\
\hline flute (флейта) & $\begin{array}{l}\text { bored, like worms of like plati- } \\
\text { nuт, into the thick thick toffee } \\
\text { gold and silver (ввинтились, } \\
\text { словно платиновые черви в } \\
\text { сладчайшую изобильную plott } \\
\text { из золота и серебра), such bliss } \\
\text { (невероятнейшее наслаждение) }\end{array}$ & - & $\begin{array}{c}\text { performed an arabesque } \\
\text { (исполнила арабеску) }\end{array}$ \\
\hline organ (орган) & - & belt out (взреветь) & $\begin{array}{c}\text { electric (электроорган), elec- } \\
\text { tronic (электронный), } \\
\text { a thirty-twofoot ріре } \\
\text { (тридиатидвухфутовая труба) }\end{array}$ \\
\hline horn (рожок) & - & - & mиtеd (приглушенный) \\
\hline violin (скрипка) & $\begin{array}{c}\text { a bird of like rarest spun hea- } \\
\text { venтеtal (как птица, вытканная } \\
\text { из неземных, тончайших } \\
\text { серебристых нитей), like silvery } \\
\text { wine flowing in а spaceship (как } \\
\text { серебристое вино, льющееся } \\
\text { из космической ракеть), } \\
\text { сате авоуе all the оther strings } \\
\text { (возвысившись над всеми } \\
\text { другими струнными) }\end{array}$ & - & - \\
\hline trombone (тромбон) & - & $\begin{array}{c}\text { glissading (завывающий), farted } \\
\text { (издал громкий пукающчий звук), } \\
\text { devil (дьявольский) }\end{array}$ & $\begin{array}{l}\text { crunch (изливаться), blast } \\
\text { (прорываться), gromky } \\
\text { (громкий), redgold (медный), } \\
\text { mиtеd (приглушенный) }\end{array}$ \\
\hline guitar (2umapa) & - & $\begin{array}{c}\text { twanging (гнусавый), } \\
\text { very teепаge (для одних } \\
\text { тинейджеров), with the voluте } \\
\text { turned ир (на полную громкость) }\end{array}$ & $\begin{array}{c}\text { electronic (электронная), elec- } \\
\text { tric (электрогитара) }\end{array}$ \\
\hline $\begin{array}{l}\text { harpsichord } \\
\text { (клавесин) }\end{array}$ & $\begin{array}{l}\text { lovely (прекрасный), elegant } \\
\text { гососо (красивый пассаж) }\end{array}$ & untuned (расстроенный) & rosewood (из розового дерева) \\
\hline
\end{tabular}


О кон ч ан и е табл.

\begin{tabular}{|c|c|c|c|}
\hline 1 & 2 & 3 & 4 \\
\hline oboе (гобой) & $\begin{array}{l}\text { bored, like worms of like plati- } \\
\text { nuт, into the thick thick toffee } \\
\text { gold and silver (ввинтились, } \\
\text { словно платиновые черви в } \\
\text { сладчайшую изобильную plott } \\
\text { из золота и серебра), such bliss } \\
\text { (невероятнейшее наслаждение), } \\
\text { sketched a diffident flourish } \\
\text { (изобразили робкую надежду) }\end{array}$ & - & - \\
\hline $\begin{array}{l}\text { saxophone } \\
\text { (саксофон) }\end{array}$ & - & - & - \\
\hline $\begin{array}{l}\text { kettledrums } \\
\text { (литавры) }\end{array}$ & & $\begin{array}{c}\text { blast (прорываться) } \\
-\end{array}$ & $\begin{array}{c}\text { gromky (громкий), a slack roll } \\
\text { (дробь) }\end{array}$ \\
\hline clarinet (кларнет) & - & - & $\begin{array}{c}\text { in a descending passage } \\
\text { (угасающиии звук) }\end{array}$ \\
\hline harp (apda) & - & - & - \\
\hline bassoon (dazom) & - & - & $\begin{array}{l}\text { white pinky (розоватый), made } \\
\text { of flesh (часть моего тела), } \\
\text { right in the middle of my belly } \\
\text { (рос из середины живота) }\end{array}$ \\
\hline gong (гонг) & - & - & - \\
\hline cymbal (ичмкала) & - & - & - \\
\hline $\begin{array}{c}\text { jangles } \\
\text { (колокольчики) }\end{array}$ & - & - & - \\
\hline viola (альт) & - & - & - \\
\hline reеd (свирель) & - & skirling (пронзительные звуки) & - \\
\hline tube (myбa) & - & - & - \\
\hline shawm (дудка) & - & skirled (пронзительно дудела) & - \\
\hline
\end{tabular}

\section{Заключение}

Анализ вербальной репрезентации музыкальных инструментов в художественной картине мира Энтони Бёрджесса продемонстрировал уникальность индивидуально-авторского восприятия и отражения музыки.

При описании музыкальных инструментов в художественных текстах Э. Бёрджесса наблюдается ярко выраженная метафоризация контекстов. Так, например, звучание струнных инструментов уподобляется шелковой сети или золотой клетке (a cage of silk around $m y$ bed), в которую попадает слушатель, становясь невольным заложником мелодии, а сила звука и воздействия на слушателя ударных и медных духовых отождествляются с бурной рекой, которая, беря начало от маленького ручейка, пробивает путь, превращаясь в бушующий поток, поглощающий и уносящий за собой (pouring in miles up through the wall).

Музыкальные инструменты также наделяются способностями, свойственными живым существам вести диалог, беседу с другими представителями своего класса (govoreet away at the rest of the orchestra). Струнные музыкальные инструменты, поначалу скрываясь - from under my bed (из-под кровати), вступают «в беседу» с остальным оркестром (the rest of the orchestra) и т. д. Присутствует оценочная составляющая, отображающая удовольствие от прослушивания музыки или, напротив, неприятие звучания того или иного музыкального инструмента.

Кроме того, в анализируемых контекстах отмечается указание на высоту и громкость звучания музыкальных инструментов (middle and lower strings, bass strings, gromky и др.), их местоположение (around my bed, from under my bed и др.), цвет (white pinky), материал изготовления (redgold и др.).

\section{ЛИТЕРАТУРА}

1. Вайсгербер Л. Родной язык и формирование духа. М. : Едиториал УРСС, 1993. 232 с.

2. Лютикова В. Д. Языковая личность и идиолект. Тюмень : Изд-во ТГУ, 1999. 188 с.

3. Попова 3. Д., Стернин И. А. Когнитивная лингвистика : учеб. пособие. М. : АСТ: Восток-Запад, 2007. $315 \mathrm{c}$.

4. Гришаева Л. И., Стернин И. А., Стернина М. А. Предисловие // Специфика деятельности коммуникантов в межкультурной среде. Воронеж, 2009. С. 3-15. 
5. Collins Online Dictionary. URL: https://www. collinsdictionary.com/dictionary/english/

6. Burgess A. Earthly Powers. Random House, 2012. $656 \mathrm{p}$.

7. Бёрджесс Э. Силы земные. URL: https://www. proza.ru/2013/08/05/97/

8. Burgess A. Time for a tiger. Heinemann, 1968. 214 p.

9. Бёрджесс Э. Время тигра / пер. с англ. Е. В. Нетесовой. М. : Центрполиграф, 2002. 237 с. $288 \mathrm{p}$.

10. Burgess A. A Clockwork Orange. M.: KAPO, 2015.

11. Бёрджесс Э. Заводной апельсин / пер. с англ. В. Бошняка. М. : АCТ, 2010. 226 с.

12. Коробко Л. В. Метафорические образы музыки в индивидуально-авторской картине мира Э. Бёрджесс // Современные лингвистические и методико-дидактические исследования. 2019. Вып. 2 (42). С. 61-69.

13. The Longman Dictionary of Contemporary English Online. URL: http://www.ldoceonline.com/

14. Burgess A. Tremor of Intent. W.W. Norton \& Company, 2013. 272 p.

15. Бёрджесс Э. Трепет намерения / пер. с англ. А. Д. Смолянского. М. : АСТ, 2010.320 с.

16. Burgess $A$. One hand clapping. Bloomsbury Publishing, 2015. $80 \mathrm{p}$.

17. Бёрджесс Э. Однорукий аплодисмент / пер. с англ. Е. В. Нетесовой. М. : Центрполиграф, 2002. 223 с.

\section{REFERENCES}

1. Vajsgerber L. Rodnoj jazyk i formirovanie duha [Native language and spirit formation]. Moscow: Editorial URSS, 1993. 232 p.

2. Ljutikova V. D. Jazykovaja lichnost'i idiolect [Language personality and idiolect]. Tjumen': Izd-vo TGU, 1999. $188 \mathrm{p}$.

Военно-воздушная академия имени Н. Е. Жуковского и Ю. А. Гагарина

Коробко Л. В., кандидат филологических наук, преподаватель кафедры иностранных языков

E-mail:l.v.ledeneva@mail.ru

Поступила в редакциюю 19 мая 20212.

Принята к публикаџии 15 июня 20212.

\section{Для цичтирования:}

Коробко Л. В. Музыкальные инструменты в художественной картине мира Э. Бёрджесса // Вестник Воронежского государственного университета. Серия: Лингвистика и межкультурная коммуникация. 2021. № 3 . C. 73-80. DOI: https://doi.org/10.17308/lic.2021.3/3583
3. Popova Z. D., Sternin I. A. Kognitivnaja lingvistika : ucheb. posobie [Cognitive linguistics: educational edition]. Moscow: AST: Vostok-Zapad, 2007. 315 p.

4. Grishaeva L. I., Sternin I. A., Sternina M. A. Predislovie [Preface]. In: Specifika dejatel'nosti kommunikantov $v$ mezhkul'turnoj srede. Voronezh, 2009. Pp. 3-15.

5. Collins Online Dictionary. Available at: https:/www. collinsdictionary.com/dictionary/english/

6. Burgess A. Earthly Powers. Random House, 2012. $656 \mathrm{p}$.

7. Bjordzhess Je. Sily zemnye [Earthly Powers]. Available at: https://www.proza.ru/2013/08/05/97/

8. Burgess A. Time for a tiger. Heinemann, 1968. $214 \mathrm{p}$.

9. Bjordzhess Je. Vremja tigra [Time for a tiger]. Translated by E. V. Netesova. Moscow: Centrpoligraph, 2002. 237 p.

10. Burgess A. A Clockwork Orange. KARO, 2015. 288 p.

11. Bjordzhess Je. Zavodnoj apel'sin [A Clockwork Orange]. Translated by V. Boshnyak. ACT, 2010. 226 p.

12. Korobko L. V. Metaforicheskie obrazy muzyki v individual'no-avtorskoj kartine mira Je. Bjordzhessa [Metaphorical images of music in the individual-and-author's world image of A. Burgess]. In: Sovremennye lingvisticheskie i metodiko-didakticheskie issledovanija. 2019. No. 2 (42). Pp. 61-69.

13. The Longman Dictionary of Contemporary English Online. Available at: http://www.ldoceonline.com/

14. Burgess A. Tremor of Intent. W.W. Norton \& Company, 2013. $272 \mathrm{p}$.

15. Bjordzhess Je. Trepet namerenija [Tremor of Intent]. Translated by A. D. Smolyansky. ACT, 2010. 320 p.

16. Burgess A. One hand clapping. Bloomsbury Publishing, 2015. $80 \mathrm{p}$.

17. Bjordzhess Je. Odnorukij aplodisment [One hand clapping]. Translated by E. V. Netesova. Moscow: Centrpoligraph, 2002. $223 \mathrm{p}$.

Air Force Academy named after N. E. Zhukovsky and Yu. A. Gagarin

Korobko L. V., Candidate of Philology, Lecturer of the Foreign Languages Department

E-mail: l.v.ledeneva@mail.ru

Received: 19 May 2021

Accepted: 15 June 2021

For citation:

Korobko L. V. Musical instruments in the literary world view of Anthony Burgess. Proceedings of Voronezh State University. Series: Linguistics and Intercultural Communication. 2021. No.3. Pp. 73-80. DOI: https://doi.org/10.17308/ lic. $2021.3 / 3583$ 